\title{
O AFILHAMENTO DA AVEIA AFETADO PELA QUALIDADE DA LUZ EM PLANTAS SOB COMPETIÇÃ̃O ${ }^{1}$
}

\section{OAT TILLERING AFFECTED BY LIGHT QUALITY, IN PLANTS UNDER COMPETITION}

\author{
Milton Luiz de Almeida ${ }^{2}$ Claudio Mario Mundstock ${ }^{3}$
}

RESUMO

As plantas de aveia, quando cultivadas em comunidades, podem mudar sua morfologia nos primeiros estádios de desenvolvimento, devido à absorção diferencial da luz vermelha $(V)$ e vermelha extrema (Ve). Objetivando identificar mudanças no desenvolvimento da aveia pela modificação na razão entre a luz $V e$ Ve, foram conduzidos três experimentos com aveia (cv.UFRGS 15). A densidade variou de 300 a $350 \mathrm{pl} / \mathrm{m}^{2}$, sob condições naturais de radiação, durante o inverno, no sul do Brasil. No primeiro experimento, foram colocados filtros azuis entre as linhas de plantas para diminuir a qualidade da luz, entre os estádios 1.1 e 3.1 da escala Haun. No segundo experimento, baixas densidades de fluxo de luz V (660nm) e Ve (730nm) foram suplementadas durante o dia, a diferentes distâncias. No terceiro experimento, baixos fluxos de $V$ e Ve também foram suplementadas, mas em dois períodos distintos: da emergência ao estádio 2.1 e do estádio 2.1 a 4.1. O uso de filtro azul e a suplementação de luz Ve determinaram menor emissão de afilhos e afilhos de menor massa seca (MS). Isso não foi verificado no terceiro experimento, no qual as melhores condições químicas possivelmente diminuíram a magnitude do efeito da luz. Já a suplementação com luz vermelha determinou maior emissão e afilhos de maior MS, devido a menor priorização da acumulação de MS no colmo principal.

Palavras-chave: luz vermelha e vermelha extrema, emissão de afilhos, acúmulo de massa seca, aveia.

\section{SUMMARY}

Oat plants grown in communities can change their morphology at early stages of development because of differential light absorption on the red and far-red wavelengths. This was studied in open air experiments with oat cultivar UFRGS 15, sown from 300 to 350 plants $/ \mathrm{m}^{2}$, under natural radiation conditions, in wintertime, in Southern Brazil. In the first experiment, blue filters were placed between plant rows in order to decrease light quality, between Haun stages 1.1 and 3.1. For second experiment, low fluence of red (660nm) e far-red (730nm) light were supplemented during the day to increase (red) and decrease (far-red) respectively the light quality. This was done between Haun stage 1.1 to 3.1, at two distances from the plants. In the third experiment, red and far-red light were also supplemented but for two different periods: emergence to Haun stage 2.1 and Haun stage 2.1 to 4.1. The blue filters and far-red supplementation (expts 1 and 2) induced plants to emit less tillers and tillers with less dry mass but was not seen in experiment 3 , when soil chemical conditions were better than the other experiments. With red supplementation, plants emitted more tillers with more dry mass. Under these conditions, the mass ratio mainstem/tiller was less proeminent than under blue filters and far-red supplementation.

Key words: red and far red light, tiller emition, dry mass allocation, oat.

\section{INTRODUÇÃO}

A radiação solar é a fonte de energia para a fotossíntese e atua como um fator ambiental que regula o crescimento e o desenvolvimento das plantas (WEI \& DENG, 1996). A absorção da luz vermelha (660nm) (V) e a não absorção da luz vermelha extrema $(730 \mathrm{~nm})$ (Ve) pela clorofila modificam intensamente a disponibilidade de radiação nessas faixas nos diferentes extratos de uma

\footnotetext{
${ }^{1}$ Extraído de parte da tese de doutorado do primeiro autor

${ }^{2}$ Engenheiro Agrônomo, Doutor, Professor da Faculdade de Agronomia da Universidade do Estado de Santa Catarina, 88520-000, CP 281, Lages, SC. E-mail: milton@ cav.udesc.br Autor para correspondência. Bolsista do CNPq.

${ }^{3}$ Engenheiro Agrônomo, PhD., Professor da Faculdade de Agronomia da Universidade Federal do Rio Grande do Sul. CP 776, 91501970, Porto Alegre, RS. E-mail: cmmunds@vortex.ufrgs.br. Bolsista do CNPq.
} 
comunidade, o que é detectado por mecanismos específicos das plantas. Em comunidades formadas por plantas da mesma espécie, algumas alterações morfológicas, como por exemplo, o crescimento do caule, são atribuídas à proximidade com outras plantas, sendo que, em dicotiledôneas, isso é detectado bem antes do início de sombreamento mútuo. Essa constatação conduziu BALLARÉ $\boldsymbol{e} \boldsymbol{t} \boldsymbol{a l}$. (1987) a proporem que a radiação vermelha extrema refletida pelas folhas podia atuar como um sinal precoce da competição que ocorreria no desenvolvimento da comunidade e que este efeito podia ser observado antes de qualquer redução na radiação fotossinteticamente ativa. Portanto, sinais de luz percebidos por receptores específicos, podem desempenhar função fundamental na detecção do nível de competição que as plantas irão encontrar, principalmente, quando a competição tende a ser intensa e a qualidade da luz é a única informação dessa futura competição (SCHMITT \& WULF, 1993).

Os receptores são moléculas que transferem a excitação eletrônica, causada pela luz, em sinal celular. Através de uma variedade de vias de tradução, o sinal original, que contém a informação sobre a luz ambiente, altera o metabolismo celular e influencia o desenvolvimento das plantas (BALLARÉ et al., 1987). Entre os receptores, o mais estudado é o fitocromo, que detecta a radiação na faixa do vermelho $(\mathrm{V})$ e do vermelho extremo $(\mathrm{Ve})$. $\mathrm{O}$ fitocromo está ligado às mudanças na morfologia de plantas em competição, podendo afetar a disponibilidade dos recursos necessários para o crescimento e também modificar a luz ambiente que é utilizada pelas plantas na determinação do padrão de crescimento (BALLARÉ et al., 1992). Desse modo, a razão V:Ve e a taxa de fluxo percebida pelo caule das plantas conduzem informações da proximidade entre as plantas e induzem, em cada uma, alterações na morfologia e na alocação de assimilados (BALLARÉ $\boldsymbol{e t} \boldsymbol{a l}$., 1992).

Uma das modificações morfológicas mais expressivas no início do desenvolvimento da aveia é o número e tamanho dos afilhos. Como a qualidade da luz modula precocemente o alongamento do caule, também pode modular a capacidade dos cereais em emitir e produzir afilhos férteis. As interrelações de luz com a produção de afilhos podem desempenhar função primordial na competição entre indivíduos, pois a estrutura da comunidade é influenciada pelo grau de desenvolvimento dos afilhos das plantas. Por essa razão, a análise em comunidades é completamente diferente da análise de plantas isoladas.
A importância dos afilhos caracteriza-se pela participação desses como parte dos componentes do rendimento das plantas e como prováveis supridores de assimilados ao colmo principal (MEROTTO JUNIOR, 1995). O número de afilhos férteis em cereais depende das condições ambientais presentes durante a iniciação do primórdio do afilho e em estádios de desenvolvimento subseqüentes (até o florescimento). Estresses ambientais durante a emergência dos afilhos podem inibir a sua formação e, em estádios posteriores, causar o seu aborto (MAAS et al., 1994).

O afilhamento está relacionado à dominância apical, isso porque esta modula o crescimento de órgãos laterais (afilhos), sendo o grau dessa modulação dependente do genótipo, do ambiente e da idade da planta (MARTIN,1987). A dominância apical é influenciada pela razão V:Ve da radiação incidente (BALLARÉ et al., 1992; SCHMITT \& WULFF, 1993). No entanto, os mecanismos pelos quais essa razão influencia a dominância apical são ainda desconhecidos (MARTIN, 1987). A luz pode alterar a concentração de reguladores de crescimento e de carboidratos e afetar o transporte destes dentro da planta (MARTIN, 1987). Em feijão, a luz diminuiu a concentração de ácido indol acético (AIA) no ápice e aumentou a concentração na região basal (MARTIN,1987). Ao contrário, JONES et al. (1991) argumentaram que apenas o decréscimo da concentração desse regulador não seria suficiente para modificar a taxa de crescimento das plantas. Por sua vez, ANDERSEN (1976) constatou que com o aumento da radiação fotossinteticamente ativa ocorreu diminuição da dominância apical e sugeriu que esse resultado decorreu da grande síntese de AIA em ervilha. Estas relações entre fitocromo e reguladores vegetais que afetam o crescimento do caule também podem afetar a emissão e manutenção dos afilhos, pois alterariam a dominância apical e, conseqüentemente, os afilhos.

$\mathrm{O}$ presente trabalho teve como objetivo verificar se a modificação da qualidade da luz interfere na emissão de afilhos, bem como na sua acumulação de massa seca.

\section{MATERIAL E MÉTODOS}

Foram conduzidos três experimentos, sendo o primeiro realizado com filtros visando a modificar a qualidade da luz através da diminuição da radiação na faixa do vermelho nas entrelinhas de cultivo. Os outros dois experimentos foram realizados com suplementação luminosa com luz vermelha 
(V) e com luz vermelha extrema (Ve). Em um dos experimentos, foi testado o efeito da suplementação luminosa a diferentes distâncias das plantas e, em outro, o efeito da luz $\mathrm{V}$ e Ve em diferentes períodos de desenvolvimento.

Os experimentos foram conduzidos em Porto Alegre, RS, em telado com a cultivar de aveia UFRGS 15. As plantas foram cultivadas em caixas de madeira com 1,2m de largura, 1,5m de comprimento e $30 \mathrm{~cm}$ de altura. Foram semeadas seis linhas orientadas na direção norte-sul, num espaçamento entrelinhas de $17 \mathrm{~cm}$. As quatro linhas centrais constituíram a área útil e cada uma dessas linhas foram consideradas como uma repetição, sendo cada repetição constituída por 20 plantas em competição. O delineamento experimental utilizado foi o completamente casualizado. As plantas, de todos os experimentos, foram cultivadas em um substrato constituído da mistura uniforme de solo mineral e cama de aviário. O substrato, utilizado no primeiro e no segundo experimentos, apresentava as seguintes características: $26 \%$ de argila; 5,4 de $\mathrm{pH}$ (em água); 20mg. $\mathrm{kg}^{-1}$ de P, $100 \mathrm{mg} . \mathrm{kg}^{-1}$ de K, 25g. $\mathrm{kg}^{-1}$ de matéria orgânica, $0,4 \mathrm{cmo} \ell_{\mathrm{c}} \cdot \mathrm{kg}^{-1}$ de $\mathrm{Al}, 2,4 \mathrm{cmo} \ell_{\mathrm{c}} \cdot \mathrm{kg}^{-1} \mathrm{de}$ $\mathrm{Ca}$ e; $1,1 \mathrm{cmo} \ell_{\mathrm{c}} \cdot \mathrm{kg}^{-1}$ de $\mathrm{Mg}$. Já o substrato utilizado no experimento 3 apresentava as seguintes características: $11 \%$ de argila; pH: 6,6 (em água); 113mg. $\mathrm{kg}^{-1}$ de P; 279mg. $\mathrm{kg}^{-1}$ de K; 106g. $\mathrm{kg}^{-1}$ de matéria orgânica; sem $\mathrm{Al} ; 17,7 \mathrm{de} \mathrm{cmo} \ell_{\mathrm{c}} \cdot \mathrm{kg}^{-1} \mathrm{de} \mathrm{Ca}$; $0,8 \mathrm{cmo} \ell_{\mathrm{c}} \cdot \mathrm{kg}^{-1} \mathrm{de} \mathrm{Mg}$.

O primeiro experimento foi semeado em 08 de maio de 1996 e a emergência ocorreu seis dias após, sendo a densidade de $300 \mathrm{p} \ell . \mathrm{m}^{-2}$ obtida através de desbaste de plântulas. Os tratamentos foram aplicados quando as plântulas apresentavam uma folha completamente expandida e foram retirados 16 dias após a sua aplicação, no estádio 3.1 da escala Haun (23 dias após a emergência). No período de realização desse experimento, a temperatura média máxima, média mínima e média foram $21,5^{\circ} \mathrm{C}, 13,1^{\circ} \mathrm{C}$ e $17,3^{\circ} \mathrm{C}$, respectivamente.

Os tratamentos aplicados foram: filtro plástico transparente e filtro de acetato azul. Tiras desses filtros com $5,0 \mathrm{~cm}$ de largura e $1,5 \mathrm{~m}$ de comprimento foram colocadas no sentido vertical e fixadas com palitos, a $8,5 \mathrm{~cm}$ das linhas de semeadura. Ao utilizar esses filtros, na direção vertical, exatamente entre as linhas de cultivo e não sombreando as plantas na linha, objetivou-se alterar a qualidade da luz refletida pelas plantas e pelo solo. A transmitância dos filtros foi determinada em espectrofotômetro marca Beckman, modelo DU65, entre os comprimentos de onda de 400 a $800 \mathrm{~nm}$, a intervalos de $40 \mathrm{~nm}$. O filtro transparente apresentou transmitância de $85 \%$ para todos os comprimentos de onda. Já o filtro azul apresentou transmitância de $22 \%$ na faixa do vermelho e $43 \%$ para o vermelho extremo. Para o azul, a transmitância foi de aproximadamente $80 \%$. O filtro transparente, por apresentar transmitância de $85 \%$ para todos os comprimentos de onda avaliados, foi considerado como o tratamento testemunha. Já o filtro azul, por reduzir mais intensamente a radiação na faixa do vermelho ( $78 \%$ de redução) foi considerado como um tratamento que diminuiu a qualidade da luz.

O desenvolvimento das plantas foi acompanhado pela escala proposta por HAUN (1973), descrevendo o colmo principal e os afilhos separadamente. A denominação de folhas e afilhos foi adaptada do padrão utilizado por MASLE (1985). Os afilhos foram denominados pela letra A, seguido do número da folha de cujo nó são originados. Dessa forma: CP - colmo principal; A0 - afilho originado do nó do coleoptile; A1 - afilho originado do nó da primeira folha do CP; A1.1 - afilho originado do nó da primeira folha do A1; An - afilho originado do nó da enésima folha do $\mathrm{CP}$.

Os tratos culturais foram realizados de forma que não houvesse interferência sobre o desenvolvimento das plantas. No estádio 3,1 da escala Haun (23 dias após a emergência), foi aplicado nitrogênio na dose de $60 \mathrm{~kg} \cdot \mathrm{ha}^{-1}$ de N. A coleta das plantas foi realizada 37 dias após a emergência, no estádio 5.4 da escala Haun. Devido às características dos filtros, não foi necessária a sua substituição no decorrer da aplicação dos tratamentos.

O segundo e o terceiro experimentos foram realizados de forma similar ao primeiro, mas utilizando sementes pré-germinadas. A prégerminação foi realizada a uma temperatura aproximada de $23^{\circ} \mathrm{C}$ e $100 \%$ de teor de água. As plântulas, apresentando a protusão da radícula, foram plantadas utilizando-se pinça e régua. $\mathrm{O}$ espaçamento entre sementes foi de $1,7 \mathrm{~cm}$ entre si, o que proporcionou uma densidade de 346 plântulas por metro quadrado.

$\mathrm{O}$ segundo experimento foi semeado em 12 de setembro de 1996 e a emergência da primeira folha ocorreu em três dias. Os tratamentos desse experimento foram: a) suplementação com luz vermelha (V) direta (plantas que estavam embaixo da luz V); b) suplementação com luz V a $180 \mathrm{~cm}$ (plantas que estavam a $180 \mathrm{~cm}$ da fonte de luz); c) suplementação com luz vermelha extrema (Ve) direta (as plantas estavam embaixo da luz Ve) e; d) suplementação com luz Ve a $180 \mathrm{~cm}$ (as plantas estavam a $180 \mathrm{~cm}$ da fonte de luz).

A suplementação luminosa das plantas foi realizada nos tratamentos a e c. Já os tratamentos b e $\mathrm{d}$ foram obtidos pela coleta de plantas em caixas 
vizinhas aos tratamentos a e c, mas que se distanciavam $180 \mathrm{~cm}$ da fonte de luz. Com isso, pretendiase verificar o efeito da suplementação com luz a uma distância maior. A adição de luz foi mantida do estádio 1,1 até o 3,1 da escala Haun (de 6 até 16 dias após a emergência). A suplementação com luz V e luz Ve foi feita durante o dia, das 7 às 18 horas.

A suplementação de luz vermelha foi feita através da conjugação de quatro lâmpadas fluorescentes de 20w acopladas em uma calha e duas folhas de celofane vermelho, colocadas imediatamente abaixo das lâmpadas. A calha foi disposta transversalmente à direção das linhas das plantas, $40 \mathrm{~cm}$ acima delas. A suplementação com luz Ve foi obtida através de dois conjuntos, cada qual com uma lâmpada incandescente de $40 \mathrm{~W}$ e com duas folhas de celofane azul e duas folhas de celofane vermelho, colocadas imediatamente abaixo de cada lâmpada. Os dois conjuntos de luz Ve foram dispostos $40 \mathrm{~cm}$ acima das linhas de cultivo e distribuídos de forma equiidistante na largura das caixas. A densidade de fluxo aproximada da luz $\mathrm{V}$ e da luz Ve é de 0,012w. $\mathrm{m}^{-2} \cdot \mathrm{nm}^{-1}$ (CARDOSO, 1995) o que equivale respectivamente a $0,055 \mathrm{mo} \ell . \mathrm{m}^{-2} . \mathrm{s}^{-1}$ e $0,060 \mathrm{mo} \ell$. $\mathrm{m}^{-2} \cdot \mathrm{s}^{-1}$ conforme transformação proposta por THIMIJAN \& HEINS (1983). Essa quantidade de luz é considerada baixa (TAIZ \& ZEIGER, 1991). O celofane, nos dois tipos de suplementação, foi substituído a cada quatro dias, à medida em que havia diminuição de sua coloração.

Plantas invasoras e pragas foram controladas imediatamente após o seu aparecimento, de forma que não houvesse qualquer interferência sobre as plântulas. A adubação nitrogenada foi realizada no estádio 3.1 da escala Haun (16 dias após a emergência), na dose de $60 \mathrm{~kg} \cdot \mathrm{ha}^{-1}$ de nitrogênio. A coleta das plantas foi realizada 30 dias após a emergência, no estádio 5.6 da escala Haun. No período de realização desse experimento, a temperatura média máxima, média mínima e média foram $22,3^{\circ} \mathrm{C}, 13,4^{\circ} \mathrm{C}$ e $17,9^{\circ} \mathrm{C}$, respectivamente.

$\mathrm{O}$ terceiro experimento foi instalado em 20 de junho de 1997 com sementes pré-germinadas. A emergência da primeira folha ocorreu três dias após. O método de suplementação luminosa foi o mesmo do segundo experimento, diferindo apenas nos tratamentos, que foram: a) testemunha (sem suplementação luminosa); b) suplementação de luz $\mathrm{V}$ da emergência até o estádio 2.1 do $\mathrm{CP}$, segundo escala Haun (até 17 dias após a emergência); c) suplementação de luz $\mathrm{V}$ do estádio 2.1 até o estádio 4.1 do CP (de 17 até 32 dias após a emergência); d) suplementação de luz Ve da emergência até o está- dio 2.1 do $\mathrm{CP}$ e; e) suplementação de luz Ve do estádio 2.1 até o estádio 4.1 do CP.

De mesma forma que nos outros dois experimentos, plantas invasoras e pragas foram controladas imediatamente após o seu aparecimento. A adubação nitrogenada foi realizada no estádio 2.2 da escala Haun, na dose de $60 \mathrm{~kg} \cdot \mathrm{ha}^{-1}$ de nitrogênio. A coleta das plantas foi realizada em 07 de agosto de 1997, no estádio 6.3 da escala Haun (48 dias após a emergência). No período de realização desse experimento, a temperatura média máxima, média mínima e média foram $19,3^{\circ} \mathrm{C}, 10,4^{\circ} \mathrm{C}$ e $14,9^{\circ} \mathrm{C}$, respectivamente.

O método de coleta de plantas e de determinação das variáveis foi similar em todos os experimentos. As 20 plantas de cada repetição foram coletadas e separadas em colmo principal (CP) e afilhos, sendo os afilhos de ordem mais elevada agrupados com os afilhos primários das mesmas folhas (ex.: A1.1 junto com o A1). O CP e os afilhos foram colocados separadamente em sacos de papel para secagem em estufa de fluxo de ar contínuo, a aproximadamente $60^{\circ} \mathrm{C}$, até massa constante. As determinações realizadas foram as seguintes: massa seca (MS) do CP; MS total obtida pelo somatório de MS do CP e dos afilhos; razão de massa entre CP e afilhos = MS do CP/ MS dos afilhos; somatório de MS dos afilhos de 20 plantas = MS dos afilhos presentes nas 20 plantas amostradas; MS por afilho = obtido pela divisão entre a MS dos afilhos presentes em 20 plantas pelo número de afilhos; \% de afilhos emitidos $=$ percentual de plantas com a presença de cada um dos afilhos primários analisados.

Os dados dos experimentos foram individualmente analisados através de análise da variância. Quando alcançada significância estatística, as médias dos tratamentos foram comparadas pelo teste de Duncan em nível de 5\% de probabilidade de erro.

\section{RESULTADOS E DISCUSSÃO}

Nos três experimentos realizados, as modificações na qualidade da luz afetaram o processo de emissão de afilhos, a sua acumulação de massa seca e a distribuição de massa seca entre afilhos e o colmo principal (CP). No entanto, a amplitude desses efeitos foi afetada pelo tipo de solo utilizado e pela época de realização do experimento. $\mathrm{O}$ uso de filtro azul, ou de suplementação luminosa com luz vermelha extrema (Ve), determinou menor produção de massa seca pelos afilhos e menor emissão de afilhos (Tabelas 1 e 2).

A resposta foi mais evidente no primeiro e segundo experimentos. Já no terceiro, o solo utilizado possivelmente modificou a resposta nas variá- 
Tabela 1 - Massa seca (MS) de afilhos em 20 plantas (g), MS por afilho (mg), percentagem de afilhos emitidos, massa seca do colmo principal (CP) e razão de massa seca entre o $\mathrm{CP}$ e os afilhos de trigo em função de tratamentos com filtro transparente e azul transparente na entrelinha (primeiro experimento) e da aplicação de radiação vermelha (Ve) e vermelha extrema (Ve) a $180 \mathrm{~cm}$ e direta (segundo experimento) entre os estádios 1 e 3.1 da escala Haun. FA/UFRGS, Porto Alegre, RS, 1996.

\begin{tabular}{|c|c|c|c|c|c|c|c|c|c|c|c|c|c|c|c|}
\hline Tratamentos & $\begin{array}{l}\text { MS } \\
\text { A0** }\end{array}$ & $\begin{array}{l}\mathrm{MS} \\
\mathrm{A} 1 * *\end{array}$ & $\begin{array}{l}\text { MS } \\
\text { A2** }\end{array}$ & $\begin{array}{c}\text { MS } \\
\mathrm{A} 3 * *\end{array}$ & $\begin{array}{c}\text { MS/ } \\
\text { afilho } \\
\text { A0 }\end{array}$ & $\begin{array}{l}\text { MS/ } \\
\text { afilho } \\
\text { A1 }\end{array}$ & $\begin{array}{l}\text { MS/ } \\
\text { afilho } \\
\text { A2 }\end{array}$ & $\begin{array}{l}\text { MS/ } \\
\text { afilho } \\
\text { A3 }\end{array}$ & $\% \mathrm{~A} 0$ & $\% \mathrm{~A} 1$ & $\% \mathrm{~A} 2$ & $\% \mathrm{~A} 3$ & MS CP & $\begin{array}{l}\text { MS } \\
\text { Total }\end{array}$ & $\begin{array}{l}\text { Rel. } \\
\text { CP/ } \\
\text { afilhos }\end{array}$ \\
\hline & \multicolumn{15}{|c|}{ Primeiro Experimento } \\
\hline $\begin{array}{l}\text { Filtro } \\
\text { Transparente }\end{array}$ & $\begin{array}{l}0,39 a \\
* *\end{array}$ & $1,79 \mathrm{a}$ & $0,83 \mathrm{a}$ & $\ldots$ & $5 \mathrm{a}$ & $89 \mathrm{a}$ & $45 \mathrm{a}$ & $\ldots$ & $37,7 \mathrm{a}$ & $100 \mathrm{a}$ & $94 \mathrm{a}$ & - & $3,54 \mathrm{a}$ & $6,55 \mathrm{a}$ & $1,18 \mathrm{~b}$ \\
\hline Filtro Azul & $0,0 \mathrm{~b}$ & $1,31 \mathrm{~b}$ & $0,66 \mathrm{~b}$ & $\ldots$ & $0 \mathrm{~b}$ & $74 \mathrm{~b}$ & $38 \mathrm{a}$ & $\ldots$ & $0,0 \mathrm{~b}$ & $89 \mathrm{~b}$ & $86 a$ & $\ldots$ & $3,37 \mathrm{a}$ & $5,35 \mathrm{~b}$ & $1,72 \mathrm{a}$ \\
\hline Média & 0,195 & 1,55 & 1,32 & & 2,5 & 82 & 42 & & 18,9 & 94,5 & 90 & & 3,46 & 5,95 & 1,45 \\
\hline \multirow[t]{2}{*}{$\mathrm{CV}(\%)$} & $\begin{array}{l}3,6 \\
* * *\end{array}$ & 10,0 & $\begin{array}{l}2.9 \\
* * *\end{array}$ & & $\begin{array}{l}0,24 \\
* * *\end{array}$ & $\begin{array}{l}0,3 \\
* * *\end{array}$ & $\begin{array}{l}0,41 \\
* * *\end{array}$ & & $\begin{array}{l}11,6 \\
* * *\end{array}$ & 5,5 & 9,5 & & 7,9 & 7,97 & 7,6 \\
\hline & \multicolumn{15}{|c|}{ Segundo Experimento } \\
\hline $\begin{array}{l}\text { V } 180 \mathrm{~cm} \\
\text { V direto } \\
\text { Ve } 180 \mathrm{~cm} \\
\text { Ve direto } \\
\text { Média } \\
\text { CV }(\%)\end{array}$ & - & $\begin{array}{c}1,26 \mathrm{a} \\
0,95 \mathrm{~b} \\
0,59 \mathrm{c} \\
0,07 \mathrm{~d} \\
0,72 \\
27,3\end{array}$ & $\begin{array}{l}0,77 \mathrm{a} \\
0,59 \mathrm{ab} \\
0,66 \mathrm{a} \\
0,29 \mathrm{~b} \\
0,58 \\
6,1 \\
* * *\end{array}$ & $\begin{array}{l}0,034 \mathrm{~b} \\
0,089 \mathrm{~b} \\
0,191 \mathrm{a} \\
0,207 \mathrm{a} \\
0,130 \\
2,19 \\
* * *\end{array}$ & $\begin{array}{l}- \\
- \\
-\end{array}$ & $\begin{array}{c}73 \mathrm{a} \\
79 \mathrm{a} \\
69 \mathrm{a} \\
24 \mathrm{~b} \\
61 \\
0,77 \\
* * *\end{array}$ & $\begin{array}{l}46 \mathrm{a} \\
43 \mathrm{bc} \\
45 \mathrm{ab} \\
28 \mathrm{c} \\
41 \\
0,28 \\
* * *\end{array}$ & $\begin{array}{l}11 \mathrm{~ns} \\
20 \\
17 \\
14 \\
16 \\
0,31 \\
* *\end{array}$ & -- & $\begin{array}{r}86,2 \mathrm{a} \\
60,8 \mathrm{~b} \\
42,6 \mathrm{c} \\
9,6 \mathrm{~d} \\
49,8 \\
18,2 \\
* * *\end{array}$ & $\begin{array}{l}82,5 \mathrm{a} \\
68,8 \mathrm{ab} \\
72,5 \mathrm{ab} \\
50,0 \mathrm{~b} \\
68,5 \\
28,2\end{array}$ & $\begin{array}{l}8,9 \mathrm{c} \\
20,8 \mathrm{c} \\
55,7 \mathrm{~b} \\
71,1 \mathrm{a} \\
39,1 \\
15,3 \\
* * *\end{array}$ & $\begin{array}{l}3,91 \mathrm{~b} \\
4,49 \mathrm{ab} \\
4,54 \mathrm{a} \\
4,08 \mathrm{ab} \\
4,26 \\
5,1\end{array}$ & $\begin{array}{l}5,98 \mathrm{a} \\
6,11 \mathrm{a} \\
5,69 \mathrm{a} \\
4,65 \mathrm{~b} \\
5,61 \\
7,6\end{array}$ & $\begin{array}{c}1,91 \mathrm{~b} \\
2,79 \mathrm{~b} \\
3,09 \mathrm{~b} \\
8,14 \mathrm{a} \\
3,98 \\
57,6\end{array}$ \\
\hline
\end{tabular}

* Médias não seguidas por mesma letra na vertical, em cada experimento, diferem entre si, pelo teste de Duncan em nível de 5\% de probabilidade de erro. **A0 = afilho do nó do coleoptile; $\mathrm{A} 1$ = afilho do nó da primeira folha; $\mathrm{A} 2$ = afilho do nó da segunda folha; $\mathrm{A} 3$ = afilho do nó da terceira folha.

***Dados transformados por Raiz quadrada de X+1.

veis analisadas. Este solo encontrava-se mais fértil que o utilizado no primeiro e segundo experimentos, o que possivelmente tenha determinado menor amplitude dos resultados. Isso sugere que as plantas podem integrar diferentes sinais do ambiente para modular o seu crescimento, ou seja, da mesma forma que as plantas muito precocemente detectam o ambiente onde irão se desenvolver e se modulam para este ambiente, possivelmente as raízes façam a mesma detecção em razão do solo que estão se desenvolvendo. Em outras palavras, essas informações são avaliadas e transformadas em uma resposta morfológica. Dessa forma, os resultados obtidos no terceiro experimento indicam que, em um ambiente radicular de melhor qualidade nutricional, o efeito de modulação da emissão de afilhos e em sua acumulação de MS pela qualidade da luz é menos intenso.

Os efeitos dos tratamentos também foram detectados pela análise da acumulação de massa seca dos afilhos em 20 plantas, que reflete o número de afilhos emitidos por essas plantas e a MS individual de cada afilho. O uso de filtro azul e a suplementação de luz Ve (Tabela 1) reduziram a massa seca acumulada pelos afilhos. Esse comportamento foi decorrência tanto da menor MS acumulada por afilho como da menor emissão de afilhos. Nas plantas do terceiro experimento, isso não ocorreu (Tabela 2), pois além da interação entre a qualidade da luz e o tipo do solo, antes referido, aplicação de radiação em diferentes períodos permitiu compensação entre os afilhos emitidos, dificultando a identificação precisa dos efeitos dos tratamentos sobre a emissão e alocação de MS nos afilhos.

Os resultados obtidos, principalmente os do primeiro e segundo experimentos, evidenciam que houve efeito da qualidade da luz na determinação do número e da massa dos afilhos, pois conforme SÁNCHEZ et al. (1993), as plantas utilizam essa sinalização para determinar seu padrão de crescimento. Considerando que o filtro azul diminuiu a radiação vermelha e foi colocado de forma que não sombreasse as plantas e, que a suplementação com luz vermelha foi em densidade de fluxo muito pequena, apenas $0,055 \mathrm{moles} . \mathrm{m}^{-2} \cdot \mathrm{s}^{-1}$, fica evidente que as modificações morfológicas verificadas nos experimentos foram mediadas pelo fitocromo. Além disso, como a aplicação dos tratamentos foi feita muito cedo (de uma até três folhas) fica demonstrado que o efeito se deveu à modificação entre a razão de $\mathrm{V}$ e Ve, e não a redução na radiação fotossinteticamente ativa.

A razão da modificação de acumulação de massa seca, quando é alterada a qualidade da luz, não está esclarecida. Os poucos estudos que associam a percepção do sinal pelo fitocromo e a resposta da planta (ARNIM \& DENG,1996 e WEI \& DENG, 1996) consideram que há participação de genes que modificam as relações entre reguladores de crescimento. Dessa forma, a giberelina e a citocinina poderiam estar envolvidas na modificação da alocação 
Tabela 2 - Massa seca (MS) de afilhos em 20 plantas (g), MS por afilho (mg), percentagem de afilhos emitidos, massa seca do colmo principal (CP) e razão de massa seca entre o $\mathrm{CP}$ e os afilhos de trigo em função da suplementação com radiação vermelha e com radiação vermelha extrema em dois estádios de desenvolvimento. FA/UFRGS, Porto Alegre, RS, 1997.

\begin{tabular}{|c|c|c|c|c|c|c|c|c|c|c|c|c|c|c|c|}
\hline Tratamentos & $\begin{array}{l}\mathrm{MS} \\
\mathrm{A} 0^{* *}\end{array}$ & $\begin{array}{c}\text { MS } \\
\mathrm{A} 1^{* *}\end{array}$ & $\begin{array}{c}\text { MS } \\
\text { A2** }\end{array}$ & $\begin{array}{l}\mathrm{MS} \\
\mathrm{A}^{* *}\end{array}$ & $\begin{array}{l}\text { MS/ } \\
\text { afilho } \\
\text { A0 }\end{array}$ & $\begin{array}{l}\text { MS/ } \\
\text { afilho } \\
\text { A1 }\end{array}$ & $\begin{array}{l}\text { MS/ } \\
\text { afilho } \\
\text { A2 }\end{array}$ & $\begin{array}{l}\text { MS/ } \\
\text { afilho } \\
\text { A3 }\end{array}$ & $\% \mathrm{~A} 0$ & $\% \mathrm{~A} 1$ & $\% \mathrm{~A} 2$ & $\% \mathrm{~A} 3$ & MS CP & $\begin{array}{l}\text { MS } \\
\text { Total }\end{array}$ & $\begin{array}{l}\text { Rel. } \\
\text { CP/ } \\
\text { afilhos }\end{array}$ \\
\hline & \multicolumn{15}{|c|}{ Terceiro Experimento } \\
\hline Testemunha & $\begin{array}{l}0,58 \mathrm{a} \\
* *\end{array}$ & $2,59 \mathrm{a}$ & $1,54 \mathrm{~b}$ & $0,16 \mathrm{c}$ & $73 \mathrm{~ns}$ & $132 \mathrm{~ns}$ & $83 \mathrm{ab}$ & $19 \mathrm{~b}$ & $41,3 \mathrm{a}$ & $97,5 \mathrm{a}$ & $92,5 \mathrm{ab}$ & $11,3 \mathrm{~b}$ & $6,22 \mathrm{~b}$ & $11,09 \mathrm{a}$ & $1,29 \mathrm{bc}$ \\
\hline Ve 0 a 2.1 & $0,23 \mathrm{~b}$ & $1,67 \mathrm{~b}$ & $1,62 \mathrm{ab}$ & $0,86 a$ & 82 & 107 & $94 \mathrm{a}$ & $55 \mathrm{a}$ & $15,0 \mathrm{~b}$ & $77,5 \mathrm{c}$ & $86,3 \mathrm{~b}$ & $78,8 \mathrm{a}$ & $5,00 \mathrm{c}$ & $9,37 \mathrm{~b}$ & $1,16 \mathrm{c}$ \\
\hline Ve 2.1 a 4.1 & $0,29 \mathrm{ab}$ & $2,23 \mathrm{ab}$ & $1,30 \mathrm{~b}$ & 0,57 & 68 & 116 & $67 \mathrm{c}$ & $34 \mathrm{ab}$ & $22,5 \mathrm{ab}$ & $91,3 \mathrm{ab}$ & $97,5 \mathrm{a}$ & $82,5 \mathrm{a}$ & $6,85 \mathrm{a}$ & $11,25 \mathrm{a}$ & $1,57 \mathrm{a}$ \\
\hline V 0 a 2.1 & $0,37 \mathrm{ab}$ & $2,23 \mathrm{ab}$ & $1,89 \mathrm{a}$ & $0,49 \mathrm{~b}$ & 57 & 132 & $99 a$ & $34 \mathrm{ab}$ & $32,5 \mathrm{ab}$ & $83,8 \mathrm{bc}$ & $95,0 \mathrm{ab}$ & $73,8 \mathrm{a}$ & $5,89 \mathrm{~b}$ & $10,85 \mathrm{a}$ & $1,19 \mathrm{c}$ \\
\hline $\mathrm{V} 2.1 \mathrm{a} 4.1$ & $0,14 \mathrm{~b}$ & $2,29 \mathrm{ab}$ & $1,44 \mathrm{~b}$ & $0,46 \mathrm{~b}$ & 71 & 128 & $76 \mathrm{bc}$ & $43 a$ & $11,3 \mathrm{~b}$ & $88,8 \mathrm{ab}$ & $95,0 \mathrm{ab}$ & $57,5 \mathrm{a}$ & $6,21 \mathrm{~b}$ & $10,55 \mathrm{ab}$ & $1,44 a b$ \\
\hline Média & 0,32 & 2,20 & 1,56 & 0,51 & 70 & 123 & 84 & 37 & 24,5 & 87,8 & 93,3 & 62,8 & 6,03 & 10,6 & 1,33 \\
\hline \multirow[t]{2}{*}{ CV $(\%)$} & 6,9 & 17,99 & 12,84 & 5,7 & 1,4 & 13,3 & 12,4 & 0,65 & 27,1 & 7,8 & 7,2 & 24,5 & 6,7 & 8,75 & 10,4 \\
\hline & $* * *$ & & & $* * *$ & $* * *$ & $* * *$ & $* * *$ & $* * *$ & $* * *$ & & & $* * *$ & & & \\
\hline
\end{tabular}

* Médias não seguidas por mesma letra na vertical, em cada experimento, diferem entre si, pelo teste de Duncan em nível de 5\% de probabilidade de erro. ** A0 = afilho do nó do coleoptile; $\mathrm{A} 1$ = afilho do nó da primeira folha; $\mathrm{A} 2$ = afilho do nó da segunda folha; $\mathrm{A} 3$ = afilho do nó da terceira folha

***Dados transformados por Raiz quadrada de $\mathrm{X}+1$

de MS devido a alterações na qualidade da luz. A giberelina, porque pode alterar o alongamento celular em função de efeitos da qualidade da luz (WELLER et al., 1994; FOSTER et al., 1994; LÓPEZ-JUEZ et al., 1995; REED et al., 1996) e a citocinina por estimular a iniciação da divisão celular em afilhos (WANG \& BELOW, 1996).

Outra possibilidade é o fato de o fitocromo estar envolvido no controle de genes ligados à fotossíntese, codificando a síntese de clorofila $a / b$, pequenas subunidades da Rubisco e outros componentes do maquinário fotossintético (DALE, 1988). Dessa forma, o maior acúmulo de MS pelos afilhos, em ambiente de melhor qualidade da luz, poderia estar ligado ao maior crescimento foliar, que é devido, principalmente, ao aumento do número de células (DALE, 1988). Esses resultados corroboram o constatado por SKINNER \& NELSON (1995), de que a luz atua como um sinal precoce na divisão celular e que isso determina um maior crescimento foliar, que por sua vez está correlacionado com o aparecimento de novas folhas e afilhos (SKINNER \& NELSON, 1994a).

A modificação do padrão de acumulação de MS entre órgãos, em função da qualidade da luz, também foi detectada através da análise da razão de massa seca entre o CP e os afilhos. Essa razão tem a vantagem de integrar as variáveis de acúmulo de MS no $\mathrm{CP}$ e nos afilhos, levando em conta o número de afilhos emitidos. As plantas com maior potencial produtivo são aquelas que apresentam os menores valores para essa razão, pois demonstra que a taxa de desenvolvimento dos afilhos é similar à do CP. Isso segundo WOBETO (1994), é fundamental para que os afilhos sejam produtivos. Nos dois primeiros experimentos, o uso de filtro azul e a suplementação com Ve aumentaram a razão CP/afilhos (Tabela 1). Esses resultados indicam que os tratamentos determinaram maior priorização do $\mathrm{CP}$ em detrimento dos afilhos alterando a dominância apical. A razão entre CP e afilhos decorre da dependência dos afilhos em fotoassimilados e em nutrientes minerais. Os afilhos dependem integralmente da planta mãe até apresentarem uma folha completamente expandida e iniciarem a desenvolver suas raízes, o que começa a ocorrer após a emissão da terceira folha do CP (SKINNER \& NELSON, 1994b).

Ainda através da razão de massa seca $\mathrm{CP} /$ afilhos, pode-se verificar que os efeitos da aplicação de luz a diferentes distâncias proporcionaram respostas diferenciadas entre os tipos de suplementação. Para a luz vermelha, detectou-se efeito praticamente similar entre o tratamento que estava sob a luz direta e o que estava a $180 \mathrm{~cm}$ (Tabela 1). Já para o tratamento com luz vermelha extrema, a maior proximidade das plantas a essa fonte luminosa proporcionou maior priorização de massa seca do CP em detrimento dos afilhos, resultando numa razão de 8,14 (Tabela 1). A razão de massa seca entre o CP e os afilhos também detectou no terceiro experimento que houve maior priorização do $\mathrm{CP}$, quando se aplicou luz Ve entre os estádios 2.1 e 4.1 (Tabela 2). Apesar de não ser possível identificar precisamente o momento em que os afilhos foram emitidos, a detecção dessa maior razão neste tratamento pode estar indicando que seja entre esses dois estádios o momento em que ocorre a definição da emissão ou 
não dos afilhos, o que resultaria da maior ou menor priorização de desenvolvimento do $\mathrm{CP}$.

A principal modificação que ocorre nas plantas, quando entram em competição, é a priorização do colmo principal em detrimento dos afilhos, e a luz Ve acentua esse efeito (BALLARÉ $\boldsymbol{e t}$ al., 1990; SMITH et al., 1990; BALLARÉ et al., 1991b). Esses efeitos da luz Ve, no entanto, não haviam sido confirmados em trabalhos de campo e com cultivares brasileiras. Muitos trabalhos (CASAL et al., 1985; KASPERBAUER \& KARLEN, 1986; BARNES \& BUBBEE, 1991) já identificaram esses efeitos, mas em plantas mantidas sob condições de baixa competição entre si e/ou em ambientes controlados, como as câmaras de crescimento. Em comunidades, a qualidade da luz modifica-se intensamente, já que o aumento da área foliar das plantas determina maior absorção de luz $\mathrm{V}$, enquanto que a luz Ve é pouco absorvida. Essas modificações são detectadas quando a área foliar é ainda pequena, pois como pode ser visto na tabela 1, as principais respostas foram obtidas com os afilhos A0 e A1, que são os primeiros a serem emitidos. Assim, pode-se afirmar que as plantas detectam as modificações na qualidade da luz e as utilizam para modular o seu crescimento.

\section{CONCLUSÕES}

A qualidade da luz modula precocemente $o$ afilhamento de aveia.

O uso de filtro azul e a suplementação com luz vermelha extrema determinam menor emissão de afilhos e afilhos de menor massa seca. Já a suplementação com luz vermelha determina maior emissão de afilhos e afilhos de maior massa seca.

\section{REFERÊNCIAS BIBLIOGRÁFICAS}

ANDERSEN, A.S. Regulation of apical dominance by ethephon, irradiance and CO2. Physiologia Plantarum, Copenhagen, v.37, p.303-308, 1976

ARNIM, A. von, DENG, X.W. Light control of seedling development. Annual Review of Plant Physiology and Plant Molecular Biology, Palo Alto, v.47, p.215-243, 1996

BALLARÉ, C.L., SÁNCHEZ, R.A., SCOPEL, A.L., et al. Early detection of neighbour plants by phytochrome perception of spectral changes in reflected sunlight. Plant, Cell and Environment, Oxford, v.10, p.551-557, 1987.

BALLARÉ, C.L., SCOPEL, A.L., SÁNCHEZ, R.A. Far-red radiation reflected from adjacent leaves: an early signal of competition in plant canopies. Science, Washington, v.247, p.329-332, 1990

BALLARÉ, C.L., SCOPEL, A.L., SÁNCHEZ, R.A., $\boldsymbol{e t}$ al. Photomorphogenic processes in the agricultural environment. Photochemistry and Photobiology, Oxford, v.56, p.777788, 1992.
BARNES, C., BUGBEE, B. Morphological responses of wheat to changes in phytochrome photoequilibrium. Plant Physiology, Rockville, v.97, n.1, p.359-365, 1991.

CARDOSO, V.J.M. Germinação e fotoblastismo de sementes de Cucumis anguria: influência da qualidade da luz durante a maturação e secagem. Revista Brasileira de Fisiologia Vegetal, Londrina, v.7, n.1, p.75-80, 1995.

CASAL, J.J., DEREGIBUS, V.A., SÁNCHEZ, R.A. Variations in tiller dynamics and morphology in Lolium multiflorum Lam. vegetative and reproductive plants as affected by differences in red/far-red irradiation. Annals of Botany, London, v.56, p.533-559, 1985.

DALE, J.E. The control of leaf expansion. Annual Review of Plant Physiology and Plant Molecular Biology, Palo Alto, v.39, p.267-295, 1988.

FOSTER, K.R., MILLER F.R., CHILDS, K.L., et al. Genetic regulation of development in sorghum bicolor. VIII. Shoot growth, tillering, flowering, gibberellin biosynthesis, and phytochrome levels are differentially affected by dosage of the ma3 allele. Plant Physiology, Rockville, v.105, n.3, p.941-948, 1994.

HAUN, J.R. Visual quantification of wheat development. Agronomy Journal, Madison, v.65, n.1, p.116-119, 1973.

JONES, A.M., COCHRAN, D.S., LAMERSON, P.M. Red lightregulated growth. I. Changes in the abundance of indoleacetic acid and 22-kilodalton auxin-binding protein in the maize mesocotyl. Plant Physiology, Rockville, v.97, n.1, p.352358, 1991.

KASPERBAUER, M.J., KARLEN, D.L. Light-mediated bioregulation of tillering and photosynthate partitioning in wheat. Physiologia Plantarum, Copenhagen, v.66, p.159163, 1986.

LÓPEZ-JUEZ, E.L., KOBAYASHI, M., SAKURAI, A, et al. Phytochrome, giberellins, and hypocotyl growth. A study using the cucumber (Cucumis sativus) long hypocotyl mutant. Plant Physiology, Rockville, v.107, n.1, p.131-140, 1995.

MAAS, E.V., LESCH, S.M., FRANCOIS, L.E., et al. Tiller development in salt-stressed wheat. Crop Science, Madison, v.34, n.6, p.1594-1603, 1994.

MARTIN, G.C. Apical dominance. HortScience, Alexandria, v.22, n.5, p.824-833, 1987.

MASLE, J. Competition among tillers in winter wheat: consequences for growth and development of the crops. In NATO ADVANCED RESEARCH WORKSHOP ON WHEAT GROWTH AND MODELLING, 1984, Bristol. Proceedings.... New York : Plenum, 1985. p.33-54. (NATO ASI Serie A. Live Science, 86)

MEROTTO JUNIOR, A. Processo de afilhamento e crescimento de raízes de trigo afetados pela resistência do solo. Porto Alegre-RS, 1995. 114p. Dissertação (Mestrado em Fitotecnia ) - Programa de Pós-graduação em Fitotecnia, Universidade Federal do Rio Grande do Sul, 1995.

REED, J.W., FOSTER, K.R., MORGAN, P.W., et al Phytochrome b affects responsiveness to gibberellins in Arabidopsis. Plant Physiology, Rockville, v.112, n.1, p.337342, 1996. 
SÁNCHEZ, R.A., CASAL, J.J., BALLARÉ, C.L., et al. Plant responses to canopy density mediated by photomorphogenic processes. In: INTERNATIONAL CROP SCIENCE CONGRESS, 1, 1993, Ames. Proceedings... Madison : Crop Science Society of America, 1993. 895p. p.779-786.

SCHMITT, J., WULFF, R.D. Light spectral quality phytochrome and plant competition. Trends in Ecology and Evolution, Victoria, v.8, p.47-51, 1993.

SKINNER, R.H., NELSON, C.J. Elongation of the grass leaf and its relationship to the phyllochron. Crop Science, Madison, v.35, n.1, p.4-10, 1995

SKINNER, R.H., NELSON, C.J. Epidermal cell division and the coordination of leaf and tiller development. Annals of Botany, London, v.74, n.1, p.9-15, 1994a.

SKINNER, R.H., NELSON, C.J. Role of leaf appearance rate and the coleoptile tiller in regulation tiller production. Crop Science, Madison, v.34, n.1, p.71-75, 1994b.

SMITH, H., CASAL, J.J., JACKSON, G.M. Reflection signals and the perception by phytochrome of the proximity of neighbouring vegetation. Plant, Cell and Environment, Oxford, v.13, p.73-78, 1990.
TAIZ, L., ZEIGER, E. Plant physiology. Redwood City: B. Cummings, 1991. 565p.

THIMIJAN, R.W., HEINS, R.D. Photometric, radiometric, and quantum light units of measure: a review of procedures for interconversion. HortScience, Alexandria, v.18, n.6, p.818822, 1983.

WANG, X. BELOW, F.E. Cytokinins in enhanced growth and tillering of wheat induced by mixed nitrogen source. Crop Science, Madison, v.36, n.1, p.121-126, 1996.

WEI, N., DENG, X.W. The role of the COP/DET/FUS genes in light control of Arabidopsis seedling development. Plant Physiology, Rockville, v.112, n.3, p.871-878, 1996.

WELLER, J.L., ROSS, J.J., REID, J.B. Giberellins and phytochrome regulation of stem elongation in pea. Planta, Berlin, v.192, p.489-496, 1994.

WOBETO, C. Padrão de afilhamento, sobrevivência de afilhos e suas relações com o rendimento de grãos em trigo. Porto Alegre-RS, 1994. 102p. Dissertação (Mestrado em Fitotecnia ) - Programa de Pós-graduação em Fitotecnia, Universidade Federal do Rio Grande do Sul, 1994.

Ciência Rural, v. 31, n. 3, 2001. 